Cite this: Chem. Commun., 2014, 50,2304

Received 29th October 2013, Accepted 10th December 2013

DOI: $10.1039 / c 3 c c 48275 h$

www.rsc.org/chemcomm

\section{High gas storage capacities and stepwise adsorption in a UiO type metal-organic framework incorporating Lewis basic bipyridyl sites $\uparrow$}

\author{
Liangjun Li, ${ }^{\text {ab }}$ Sifu Tang, ${ }^{a}$ Chao Wang, ${ }^{\text {ab }}$ Xiaoxia Lv, ${ }^{\text {ab }}$ Min Jiang, ${ }^{a}$ Huaizhi Wu ${ }^{a}$ and \\ Xuebo Zhao*a
}

A UiO type MOF with Lewis basic bipyridyl sites was synthesized and structurally characterized. After being activated by Soxhlet-extraction, this MOF exhibits high storage capacities for $\mathrm{H}_{2}, \mathrm{CH}_{4}$ and $\mathrm{CO}_{2}$, and shows unusual stepwise adsorption for liquid $\mathrm{CO}_{2}$ and solvents, indicating a sequential filling mechanism on different adsorption sites.

Developing an effective system for carbon dioxide capture from anthropogenic emissions and finding appropriate mediums for energy gas (i.e., $\mathrm{H}_{2}$ and $\mathrm{CH}_{4}$ ) storage have been long term challenges, and will be increasingly urgent in future. ${ }^{1}$ Physical sorption using solid state absorbents provides efficient alternatives owing to fast kinetics and high energy efficiency. ${ }^{2}$ Indeed, some pilot plants for carbon dioxide capture and methane storage using solid state absorbents have been realized by some research groups. ${ }^{3}$

Established as a new class of crystalline porous materials, metal-organic frameworks (MOFs) provide ideal platforms for such applications due to their intriguing structures, high surface area and tuneable functional pore environments. ${ }^{4}$ In order to achieve high gas storage capacities or high selectivity, extensive efforts have been devoted to increase the affinity of frameworks with gas molecules, such as generating open metal sites $^{5}$ or tuning pore environments by immobilizing functional groups on the pore surface. ${ }^{6}$ Immobilizing functional groups appears to be a promising strategy to tune the adsorption properties, especially for enhancing $\mathrm{CO}_{2}$ binding strength by incorporating Lewis basic sites. However, the conventional strategy of anchoring the functional groups has some drawbacks. Along with the modification of the pore environments, the space occupation or blockage of functional groups always decreases the pore volume as well as specific surface areas significantly, which contrariwise lower the gas uptake capacities. $^{7}$ In this respect, the N-heterocyclic ligands are more

\footnotetext{
${ }^{a}$ Qingdao Institute of Bioenergy and Bioprocess Technology, Chinese Academy of Sciences, Shandong, 266101, China. E-mail: zhaoxb@qibebt.ac.cn; Fax: +86 0532-80662728

${ }^{b}$ University of Chinese Academy of Sciences, Beijing, 100049, China

$\dagger$ Electronic supplementary information (ESI) available: Details of experiments, IR spectra, TGA and calculation details. CCDC 968930. For ESI and crystallographic data in CIF or other electronic format see DOI: 10.1039/c3cc48275h
}

attractive due to their benefits of constructing isomorphic MOFs and incorporating functional Lewis basic sites into the pore surface without declining their original pore spaces. ${ }^{8}$

The UiO types of MOFs are an emerging class of MOFs that attract broad interest. ${ }^{9}$ The highly porous structures and excellent stability of these types of MOFs allow them to be promising materials for the targets of $\mathrm{CO}_{2}$ capture and energy gas storage. Up to now, extensive studies have been conducted based on UiO MOFs and their derivatives synthesized by functionalization/ modification on organic linkers. ${ }^{10}$ Nevertheless, the gas sorption studies on UiO type MOFs incorporating Lewis basic pyridyl sites have never been investigated so far. The outstanding structural characteristics and excellent stability of UiO type MOFs motivate us to incorporate the pyridyl moieties into the frameworks, with the anticipation that it would further enhance the gas uptake capacities by anchoring the Lewis basic sites onto the pore surface but without sacrificing its original high porosity and exceptional robustness. Herein, we synthesized a UiO MOF, $\mathrm{Zr}_{6}\left(\mu^{3}-\mathrm{O}\right)_{4}(\mathrm{OH})_{4}(\mathrm{bpdc})_{12}$ (termed as $\mathrm{UiO}(\mathrm{bpdc})$ in this communication), by using a $\mathrm{N}$-heterocyclic carboxylate ligand: 2,2-bipyridine-5,5'-dicarboxylate (bpdc), in which the bipyridyl moieties were incorporated as free Lewis basic sites. Upon being activated by Soxhlet-extraction, the adsorption properties of $\mathrm{N}_{2}, \mathrm{H}_{2}, \mathrm{D}_{2}, \mathrm{CO}_{2}$ and $\mathrm{CH}_{4}$ were examined. Afterwards, the sorption behaviours towards $\mathrm{CO}_{2}$ at $195 \mathrm{~K}$ and organic solvents at room temperature on $\mathrm{UiO}(\mathrm{bpdc})$ were investigated, and the adsorption mechanism was discussed.

$\mathrm{UiO}(\mathrm{bpdc})$ is prepared from the solvothermal reaction of the bpdc ligand with $\mathrm{ZrCl}_{4}$ via a modulated method (see experimental details in ESI, $\dagger \mathrm{S} 2$ ), and a pure phase of octahedral shaped crystals were obtained. Single crystal analysis reveals that UiO(bpdc) crystallizes in cubic space group $F m \overline{3}$ which has a lower symmetry in contrast to the commonly encountered $F m \overline{3} m$ space group in UiO series MOFs, ${ }^{11}$ because the inclusion of hetero $\mathrm{N}$ atoms in bpdc linkers lowers the symmetry of the crystal system. As expected, a six-nuclear 12-connected SBU: $\mathrm{Zr}_{6} \mathrm{O}_{4}(\mathrm{OH})_{4}\left(\mathrm{CO}_{2}\right)_{12}$, is formed by the assembly of six zirconium atoms with eight $\mu^{3}-\mathrm{O}$ or $\mu^{3}-\mathrm{OH}$ bridged oxygen atoms and twelve carboxylate groups (as shown in Fig. 1a). Due to the oxo-philic nature of the early transition 


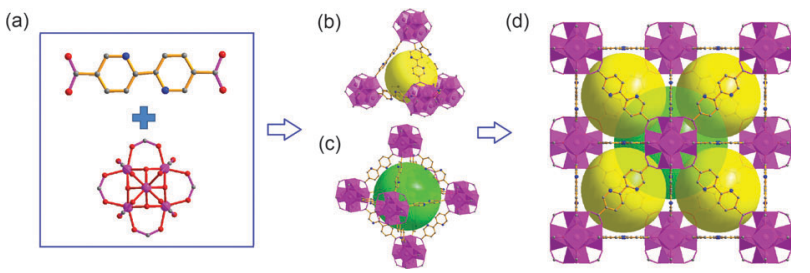

Fig. 1 (a) Ball and stick representation of the bpdc ligand and SBU: $\left[\mathrm{Zr}_{6}\left(\mu^{3}-\mathrm{O}\right)_{3}(\mathrm{OH})_{3}(\mathrm{COO})_{12}\right]$ (gray: $\mathrm{C}$; red: O; blue: N; purple: $\mathrm{Zr}$ ); (b) the tetrahedral cage; (c) the octahedral cage; (d) packing of two types of cages.

elements, the $\operatorname{Zr}(\mathrm{Iv})$ ions are preferably coordinated to the oxygen donor atoms of the carboxylate groups in bpdc, while the 2,2'-bipyridine moieties are left free, which could act as the Lewis basic sites. Then, each vertex of the 12-connected SBUs is bridged by the bpdc linkers through the carboxylate groups, forming a three-dimensional network with the $f c u$ topology. The formula of UiO(bpdc) can be determined to be $\mathrm{Zr}_{6}\left(\mu^{3}-\mathrm{O}\right)_{4}(\mathrm{OH})_{4}(\mathrm{bpdc})_{12}$ on the basis of single crystal X-ray analysis and elemental analysis. Two types of cages, the octahedral cages with a diameter of $1.6 \mathrm{~nm}$ and the tetrahedral cages with a diameter of $1.2 \mathrm{~nm}$, are formed by the assembly of the SBUs and linkers (as illustrated in Fig. 1b and c). The theoretical void ratio of the framework is $68.5 \%$, with a crystallographic density of $0.765 \mathrm{~g} \mathrm{~cm}^{-3}$.

The as synthesized sample prepared in this work is of high purity, as confirmed by good match between the simulated and experimental PXRD patterns (as shown in ESI, $\dagger$ S4). TGA analysis reveals that $\mathrm{UiO}(\mathrm{bpdc})$ is stable up to $512{ }^{\circ} \mathrm{C}$ under an $\mathrm{N}_{2}$ atmosphere (see TGA curves in ESI, $\uparrow$ S5), which is comparable with UiO-66 and its analogues, ${ }^{7 b}$ indicating its excellent thermal stability. The unvaried PXRD patterns of the samples exposed to moisture and treated by soaking in common solvents also show good chemical stability for this MOF (see PXRD patterns in ESI, $\dagger$ S4). To fully activate the as synthesized sample, we employed Soxhlet-extraction to extract the high boiling point solvents and other compounds involved in the framework, using ethanol as the extraction agent. Then, the guest molecules were removed by heating the extracted sample under ultrahigh vacuum before adsorption measurements.

The $\mathrm{N}_{2}$ isotherm measured at $77 \mathrm{~K}$ of $\mathrm{UiO}(\mathrm{bpdc})$ shows a reversible typical type-I isotherm with a pore volume of $1.057 \mathrm{~cm}^{3} \mathrm{~g}^{-1}$. The Brunauer-Emmett-Teller (BET) and Langmuir surface areas are $2646 \mathrm{~m}^{2} \mathrm{~g}^{-1}$ and $2965 \mathrm{~m}^{2} \mathrm{~g}^{-1}$, respectively (see the calculation process in ESI, $\dagger$ S7). These values are significantly higher than that of UiO-67 (BET surface area: $1877 \mathrm{~m}^{2} \mathrm{~g}^{-1},{ }^{9 a} 1575 \mathrm{~m}^{2} \mathrm{~g}^{-1}$ (ref. $9 b$ )). It is noteworthy that the experimental pore volume of $\mathrm{UiO}(\mathrm{bpdc})$ is identical to the theoretical value of UiO-67 $\left(1.05 \mathrm{~cm}^{3} \mathrm{~g}^{-1}\right)^{9 b}$ which has almost the same ligand length and SBUs, demonstrating that $\mathrm{UiO}(\mathrm{bpdc})$ is fully activated and the Soxhlet-extraction is of great help for completely extracting the guest compounds involved in the framework.

The outstanding characteristics of structures and pore environments of $\mathrm{UiO}(\mathrm{bpdc})$ enable it to possess high uptake capacities for $\mathrm{H}_{2}, \mathrm{CO}_{2}$ and $\mathrm{CH}_{4}$. As shown in Fig. 2b, it adsorbs $5.7 \mathrm{wt} \%$ of $\mathrm{H}_{2}$ at $77 \mathrm{~K}$ and $20 \mathrm{bar}$, which has not reached saturation yet. It should be pointed out that this uptake is
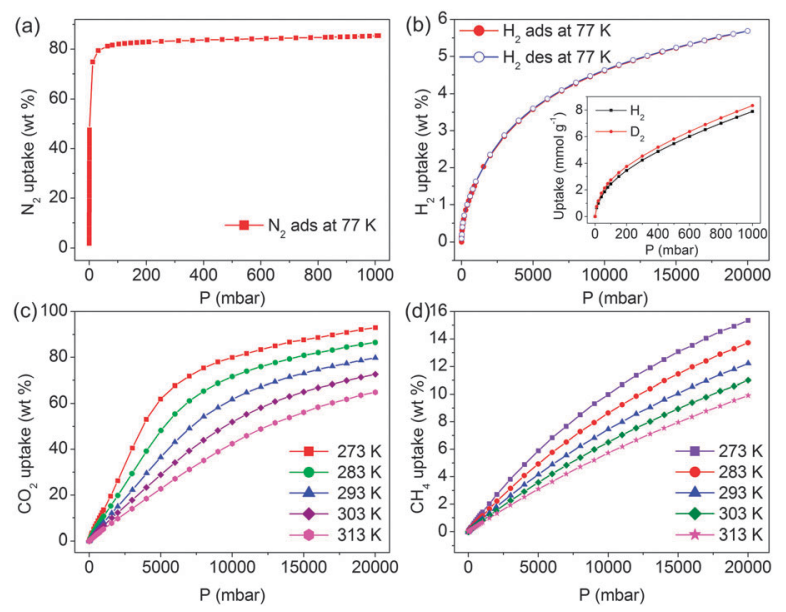

Fig. 2 Adsorption isotherms for $\mathrm{UiO}$ (bpdc). (a) $\mathrm{N}_{2}\left(77 \mathrm{~K}\right.$ ); (b) $\mathrm{H}_{2}(77 \mathrm{~K}$ ) (excess) and $\mathrm{D}_{2}$ (77 K) (inset); (c) $\mathrm{CO}_{2}(273,283,293,303$ and $313 \mathrm{~K}$ ) (excess); (d) $\mathrm{CH}_{4}(273,283,293,303$ and $313 \mathrm{~K})$ (excess).

among the top ranks of the hydrogen uptakes on MOF materials, comparable to the uptakes on NOTT- $102^{12}$ and $\mathrm{Be}_{12}(\mathrm{OH})_{12}(\mathrm{BTB})_{4} \cdot{ }^{13}$ This uptake is also $26.6 \%$ higher than that on UiO- $67^{9 a}(4.5 \mathrm{wt} \%$ at $77 \mathrm{~K}$ and 20 bar). $\mathrm{D}_{2}$ isotherm for $\mathrm{UiO}(\mathrm{bpdc}$ ) upto 1 bar at $77 \mathrm{~K}$ (see inset in Fig. 2b) shows a similar shape to $\mathrm{H}_{2}$ with $\mathrm{D}_{2} / \mathrm{H}_{2}$ ratios (mol ratio) of about 1.05 times that are the reasonable uptake ratios of $\mathrm{D}_{2}$ to $\mathrm{H}_{2}$, confirming the reliability of the above $\mathrm{H}_{2}$ adsorption measurements. ${ }^{14}$ Moreover, the uptake ratio of $\mathrm{D}_{2}$ to $\mathrm{H}_{2}$ shows an increasing trend with the decreasing pressure and reaches a maximum ratio of 1.19 at 20 mbar (as shown in Fig. S5 in ESI, $\dagger$ S8). Former studies revealed that the quantum effects of $\mathrm{D}_{2}$ and $\mathrm{H}_{2}$ adsorption in confined nano-porous structures led to the difference in their adsorption properties. ${ }^{14} \mathrm{As}$ for $\mathrm{UiO}(\mathrm{bpdc})$, the fine structure of nano-corners around SBUs might attribute to the different adsorption isotherms of $\mathrm{D}_{2}$ and $\mathrm{H}_{2}$ at low pressures. At $293 \mathrm{~K}$ and 20 bar, it absorbs $79.7 \mathrm{wt} \%$ of $\mathrm{CO}_{2}$ (as shown in Fig. 2b), corresponding to $310 \mathrm{v}(\mathrm{STP}) / \mathrm{v}$ (using a crystallographic density of $0.765 \mathrm{~g} \mathrm{~cm}^{-3}$ ). This value is the among the top uptakes of $\mathrm{CO}_{2}$ on MOF materials, comparable to the uptakes on MOF- $177^{15}$ and MIL-101 $(\mathrm{Cr})^{16}$ under the similar conditions, and is also larger than the experimental or theoretical $\mathrm{CO}_{2}$ uptake capacities on UiO-67 and UiO-68. ${ }^{9 b}$ Considering the almost identical configurations as well as theoretical pore volumes of UiO-67, the significant enhancement of $\mathrm{CO}_{2}$ uptakes on $\mathrm{UiO}$ (bpdc) could be attributed to the combinational benefits of high surface area and Lewis basic bipyridyl sites. The $\mathrm{CO}_{2}$ uptakes at 0.15 and 1 bar are 1.5 and $8.0 \mathrm{wt} \%$, respectively. These values are higher than those on MIL-101 ${ }^{16 b}$ and MOF- $177^{15 b}$ under similar conditions, but are lower than those on MOFs with narrower pore size, high dense open metal sites or $-\mathrm{NH}_{2}$ functional groups, ${ }^{17}$ indicating the different roles of surface chemistry and surface area in gas adsorption. The methane isotherms for $\mathrm{UiO}(\mathrm{bpdc})$ measured at room temperature show nearly linear trends up to $20 \mathrm{bar}$, indicating the promise of high working capacity under practical conditions (as shown in Fig. 2d). At $293 \mathrm{~K}$ and 20 bar, the adsorbed amount of $\mathrm{CH}_{4}$ is $12.2 \mathrm{wt} \%$ $\left(7.63 \mathrm{mmol} \mathrm{g}^{-1}\right)$, which is far from saturation. The methane isotherms fit well with the Langmuir equation at a higher pressure 

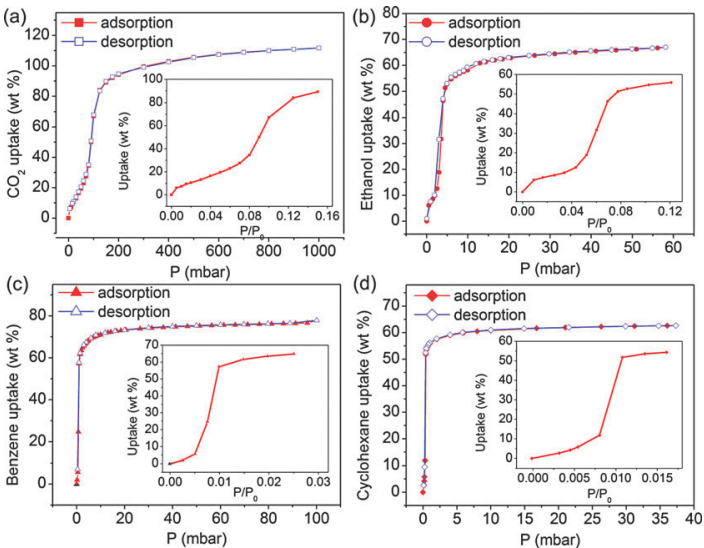

Fig. 3 (a) $\mathrm{CO}_{2}$ isotherm at $195 \mathrm{~K}$; (b) ethanol isotherm at $293 \mathrm{~K}$; (c) benzene isotherm at $293 \mathrm{~K}$; (d) cyclohexane isotherm at $293 \mathrm{~K}$.

range (see details in $\mathrm{ESI}, \dagger \mathrm{S} 10)$. The predicated methane storage capacity from Langmuir simulation is $10.52 \mathrm{mmol} \mathrm{g}^{-1}$ at $293 \mathrm{~K}$ and $35 \mathrm{bar}$, corresponding to $180 \mathrm{v}(\mathrm{STP}) / \mathrm{v}$. This value reached the DOE target of $180 \mathrm{v}(\mathrm{STP}) / \mathrm{v}$ for methane storage at ambient temperature and 35 bar, making $\mathrm{UiO}(\mathrm{bpdc})$ one of the few MOFs that meet the DOE target. Compared to the benchmark MOFs with high methane capacities, such as PCN-14, ${ }^{18}$ USTA- $20^{5}$ and MOF- $74^{19}$ etc., UiO(bpdc) exhibits better thermal and chemical stability owing to the inclusion of the $\mathrm{Zr}_{6} \mathrm{O}_{4}(\mathrm{OH})_{4}\left(\mathrm{CO}_{2}\right)_{12}$ SBUs. The high capacity and excellent stability make it a very attractive material for methane storage applications. The isosteric adsorption enthalpy $\left(Q_{\mathrm{st}}\right)$ of $\mathrm{CO}_{2}$ and $\mathrm{CH}_{4}$ on $\mathrm{UiO}(\mathrm{bpdc})$ lies in the range of 18.5-24.0 and 12.6-15 $\mathrm{kJ} \mathrm{mol}^{-1}$, respectively. These values suggest the moderate interaction strength of gas molecules with the framework, which is lower than that of MIL- $101^{16}$ but higher than that of MOF- $177 .^{15 b}$

Other than high uptake capacities, UiO(bpdc) exhibits unusual reversible stepwise isotherms for $\mathrm{CO}_{2}$ adsorption at $195 \mathrm{~K}$ and organic solvent (ethanol, cyclohexane and benzene) adsorption at room temperature (as shown in Fig. 3). Clear or obscure two-step reversible isotherms are observed for these sorbates at the low pressure range, which cannot be interpreted by simple multi-layer adsorption. It could also not be caused by pore expansion and contraction which is well documented in MIL-53 ${ }^{20}$ and TetZB, ${ }^{21}$ based on the factors, $\mathrm{UiO}(\mathrm{bpdc})$ 's network rigidity combined with non-hysteretic isotherms and identical PXRD patterns (see PXRD patterns in ESI, $\dagger \mathrm{S} 4)$. The stepwise isotherms for $\mathrm{UiO}(\mathrm{bpdc})$ could be attributed to the sequential adsorption of sorbates on different adsorption sites. The first step may be ascribed to the adsorption of sorbates on the preferred adsorption sites such as nano-corners near metal atoms because of the higher adsorption potential, while the larger second step in isotherms could be attributed to the pore filling of the rest of the pore volume. With such a sequential adsorption process, the $Q_{\mathrm{st}}$ of $\mathrm{CO}_{2}$ undergoes a two-step transformation. The first decrease in $Q_{\mathrm{st}}$ of $\mathrm{CO}_{2}$ at low loadings indicates that preferable adsorption sites are occupied firstly, while the following gradual increase of $Q_{\mathrm{st}}$ at the higher loading could be ascribed to the larger $\mathrm{CO}_{2}-\mathrm{CO}_{2}$ interactions when filling the rest of the spaces. No evident stepwise adsorption is observed for $\mathrm{CH}_{4}$ isotherms and the $Q_{\text {st }}$ plot of $\mathrm{CH}_{4}$ is relatively normal, indicating that the sequential filling mechanism is much related to the dipole moments of the sorbates.

In conclusion, a UiO type MOF with incorporated Lewis basic bipyridyl sites was synthesized by the solvothermal reaction of bpdc with $\mathrm{Zr}$ salts. The Soxhlet-extraction activation allows $\mathrm{UiO}(\mathrm{bpdc})$ to be fully evacuated. The highly porous structure combined with Lewis basic sites incorporated on the pore surface enables $\mathrm{UiO}(\mathrm{bpdc})$ to possess high uptake capacity for $\mathrm{H}_{2}, \mathrm{CO}_{2}$ and $\mathrm{CH}_{4}$. The exceptional stability and excellent adsorption capacities make this MOF a very promising material for $\mathrm{CO}_{2}$ capture and energy gas storage. Furthermore, the stepwise isotherms observed at low pressure for adsorption of $\mathrm{CO}_{2}$ at $195 \mathrm{~K}$ and adsorption of organic solvents at room temperatures reveal a sequential filling mechanism of adsorbates on different adsorption sites.

This work was supported by grants from the Natural Science Foundation of China (Grant No. 21073216 and 21173246) and the "Hundred-talent Project" (KJCX2-YW-W34) of the Chinese Academy of Sciences for the financial support.

\section{Notes and references}

1 L. Schlapbach and A. Züttel, Nature, 2011, 414, 353-358.

2 (a) T. A. Makal, J.-R. Li, W. Lu and H.-C. Zhou, Chem. Soc. Rev., 2012, 41, 7761-7779; (b) X. B. Zhao, B. Xiao, A. J. Fletcher and K. M. Thomas, J. Phys. Chem. B, 2005, 109, 8880-8888.

3 J. Zhang, P. A. Webley and P. Xiao, Energy Convers. Manage., 2008, 49, 346-356.

4 (a) M. Eddaoudi, J. Kim, N. Rosi, D. Vodak, J. Wachter, M. O'Keeffe and O. M. Yaghi, Science, 2002, 295, 469-472; (b) X. Zhao, B. Xiao, A. J. Fletcher, K. M. Thomas, D. Bradshaw and M. J. Rosseinsky, Science, 2004, 306, 1012-1015; (c) L. Li, S. Tang, X. Lv, M. Jiang, C. Wang and X. Zhao, New J. Chem., 2013, 37, 3662-3670.

5 Z. Guo, H. Wu, G. Srinivas, Y. Zhou, S. Xiang, Z. Chen, Y. Yang, W. Zhou, M. O'Keeffe and B. Chen, Angew. Chem., Int. Ed., 2011, 50, 3178-3181.

6 (a) E. Neofotistou, C. D. Malliakas and P. N. Trikalitis, Chem.-Eur. J., 2009, 15, 4523-4527; (b) H. Liu, Y. Zhao, Z. Zhang, N. Nijem, Y. J. Chabal, H. Zeng and J. Li, Adv. Funct. Mater., 2011, 21, 4754-4762. 7 (a) S. Biswas and P. Van Der Voort, Eur. J. Inorg. Chem., 2013, 2154-2160; (b) M. Kandiah, M. H. Nilsen, S. Usseglio, S. Jakobsen, U. Olsbye, M. Tilset, C. Larabi, E. A. Quadrelli, F. Bonino and K. P. Lillerud, Chem. Mater., 2010, 22, 6632-6640.

8 (a) X. Rao, J. Cai, J. Yu, Y. He, C. Wu, W. Zhou, T. Yildirim, B. Chen and G. Qian, Chem. Commun., 2013, 49, 6719-6721; (b) E. D. Bloch, D. Britt, C. Lee, C. J. Doonan, F. J. Uribe-Romo, H. Furukawa, J. R. Long and O. M. Yaghi, J. Am. Chem. Soc., 2010, 132, 14382-14384.

9 (a) S. Chavan, J. G. Vitillo, D. Gianolio, O. Zavorotynska, B. Civalleri, S. Jakobsen, M. H. Nilsen, L. Valenzano, C. Lamberti, K. P. Lillerud and S. Bordiga, Phys. Chem. Chem. Phys., 2012, 14, 1614-1626; (b) Q. Yang, V. Guillerm, F. Ragon, A. D. Wiersum, P. L. Llewellyn, C. Zhong, T. Devic, C. Serre and G. Maurin, Chem. Commun., 2012, 48, 9831-9833.

10 (a) J. L. Long, S. B. Wang, Z. X. Ding, S. C. Wang, Y. E. Zhou, L. Huang and X. X. Wang, Chem. Commun., 2012, 48, 11656-11658; (b) Q. Yang, S. Vaesen, F. Ragon, A. D. Wiersum, D. Wu, A. Lago, T. Devic, C. Martineau, F. Taulelle, P. L. Llewellyn, H. Jobic, C. Zhong, C. Serre, G. De Weireld and G. Maurin, Angew. Chem., Int. Ed., 2013, 52, 10316-10320; (c) J. B. DeCoste, G. W. Peterson, H. Jasuja, T. G. Glover, Y.-g. Huang and K. S. Walton, J. Mater. Chem. A, 2013, 1, 5642-5650.

11 (a) J. H. Cavka, S. Jakobsen, U. Olsbye, N. Guillou, C. Lamberti, S. Bordiga and K. P. Lillerud, J. Am. Chem. Soc., 2008, 130, 13850-13851; (b) H.-L. Jiang, D. Feng, T.-F. Liu, J.-R. Li and H.-C. Zhou, J. Am. Chem. Soc., 2012, 134, 14690-14693.

12 X. Lin, I. Telepeni, A. J. Blake, A. Dailly, C. M. Brown, J. M. Simmons, M. Zoppi, G. S. Walker, K. M. Thomas, T. J. Mays, P. Hubberstey, N. R. Champness and M. Schröder, J. Am. Chem. Soc., 2009, 131, 2159-2171.

13 K. Sumida, M. R. Hill, S. Horike, A. Dailly and J. R. Long, J. Am. Chem. Soc., 2009, 131, 15120-15121. 
14 (a) B. Chen, X. Zhao, A. Putkham, K. Hong, E. B. Lobkovsky, E. J. Hurtado, A. J. Fletcher and K. M. Thomas, J. Am. Chem. Soc., 2008, 130, 6411-6423; (b) X. Zhao, S. Villar-Rodil, A. J. Fletcher and K. M. Thomas, J. Phys. Chem. B, 2006, 110, 9947-9955.

15 (a) A. R. Millward and O. M. Yaghi, J. Am. Chem. Soc., 2005, 127, 17998-17999; (b) J. A. Mason, K. Sumida, Z. R. Herm, R. Krishna and J. R. Long, Energy Environ. Sci., 2011, 4, 3030-3040.

16 (a) P. L. Llewellyn, S. Bourrelly, C. Serre, A. Vimont, M. Daturi, L. Hamon, G. De Weireld, J.-S. Chang, D.-Y. Hong, Y. Kyu Hwang, S. Hwa Jhung and G. r. Férey, Langmuir, 2008, 24, 7245-7250; (b) P. Chowdhury, C. Bikkina and S. Gumma, J. Phys. Chem. C, 2009, 113, 6616-6621.

17 (a) Y.-X. Tan, Y.-P. He and J. Zhang, ChemSusChem, 2012, 5, 1597-1601; (b) S. R. Caskey, A. G. Wong-Foy and A. J. Matzger,
J. Am. Chem. Soc., 2008, 130, 10870-10871; (c) F. Wang, Y.-X. Tan, H. Yang, H.-X. Zhang, Y. Kang and J. Zhang, Chem. Commun., 2011, 47, 5828-5830.

18 S. Ma, D. Sun, J. M. Simmons, C. D. Collier, D. Yuan and H.-C. Zhou, J. Am. Chem. Soc., 2008, 130, 1012-1016.

19 H. Wu, W. Zhou and T. Yildirim, J. Am. Chem. Soc., 2009, 131, 4995-5000.

20 P. L. Llewellyn, S. Bourrelly, C. Serre, Y. Filinchuk and G. Férey, Angew. Chem., Int. Ed., 2006, 45, 7751-7754.

21 (a) P. K. Thallapally, J. Tian, M. Radha Kishan, C. A. Fernandez, S. J. Dalgarno, P. B. McGrail, J. E. Warren and J. L. Atwood, J. Am. Chem. Soc., 2008, 130, 16842-16843; (b) R. K. Motkuri, P. K. Thallapally, S. K. Nune, C. A. Fernandez, B. P. McGrail and J. L. Atwood, Chem. Commun., 2011, 47, 7077-7079. 